\title{
Michel Sirvent, Georges Perec ou le dialogue des genres
}

\section{Laura Brignoli}

\section{(2) OpenEdition}

\section{Journals}

\section{Édition électronique}

URL : http://journals.openedition.org/studifrancesi/8072

DOI : 10.4000/studifrancesi.8072

ISSN : 2427-5856

\section{Éditeur}

Rosenberg \& Sellier

\section{Édition imprimée}

Date de publication : 1 juillet 2009

Pagination : 439-440

ISSN : 0039-2944

\section{Référence électronique}

Laura Brignoli, « Michel Sirvent, Georges Perec ou le dialogue des genres », Studi Francesi [En ligne], 158 (LIII | II) | 2009, mis en ligne le 30 novembre 2015, consulté le 08 janvier 2021. URL : http:// journals.openedition.org/studifrancesi/8072 ; DOI : https://doi.org/10.4000/studifrancesi.8072

Ce document a été généré automatiquement le 8 janvier 2021.

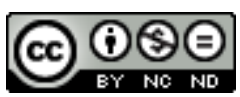

Studi Francesi è distribuita con Licenza Creative Commons Attribuzione - Non commerciale - Non opere derivate 4.0 Internazionale. 


\title{
Michel Sirvent, Georges Perec ou le dialogue des genres
}

\author{
Laura Brignoli
}

\section{RÉFÉRENCE}

MICHEL SIRVENT, Georges Perec ou le dialogue des genres, Rodopi, Amsterdam-New York, 2007 («Collection Monographique Rodopi en Littérature Française Contemporaine», 45), pp. 229.

1 L'analyse narratologique de Sirvent, qui se prévaut d'une précision terminologique tendant par moments au jargon, s'ouvre en montrant que les œuvres de cet auteur se situent dans une inter(auto)textualité s'exprimant dans quatre domaines: sociologique (c'est le cas de ses premières œuvres), ludique (après son entrée dans l'Oulipo qui a orienté de façon décisive sa production), romanesque et autobiographique, sans que l'on puisse véritablement démarquer chaque texte par une appartenance exclusive à un seul de ces quatre genres. L'illustration de ce métissage des genres est fournie par l'analyse de $W$ ou le souvenir d'enfance qui inaugure selon l'A. le courant de la Nouvelle Autobiographie caractérisée par une "confrontation hétérogénérique" et "intratextuelle", mais qui est loin de s'y en tenir de façon exclusive.

2 La confrontation constante avec la réception, qui avait fait l'objet de l'introduction, est posée aussi quand il analyse le statut de $W$ : soulignant que toute autobiographie est d'abord une narration, il met en relation cette qualité avec l'indication "récit" de ce texte qui, à première vue, met en scène, en réalité, au moins deux narrations distinctes, chacune d'elles annoncée par tout l'apparat péritextuel soigneusement analysé et dont la bipartition se reflète dans la structure binaire de la phrase. La rigueur du regard critique posé sur ce texte invite à dépasser la dichotomie du péritexte et est à même d'en interpréter la complexité en se démarquant des lectures critiques précédentes grâce aussi à la confrontation constante avec d'autres œuvres au statut similaire. La minutieuse analyse de la distribution des chapitres, des lois qui gèrent l'alternance et la 
numérotation et de l'anomalie structurelle concernant l'alternance servent aussi à mettre en évidence une béance. Comme dans La Disparition, texte qui s'inscrit en filigrane dans la deuxième partie de $W$, émerge une absence, "paradigme de l'omission" autour duquel tourne l'œuvre entier. La lisibilité et la "lecturabilité" des contraintes, les correspondances interdiégétiques et l'enchevêtrement des deux textes concourent à montrer la nécessité de dépasser la notion de genre et d'adapter toute lecture à la nature du texte en question. 